\title{
NEWS
}

\section{Crunch time for peer review in lawsuit}

A US magistrate is set to rule next week on whether the drugmaker Pfizer can force The New England Journal of Medicine (NEJM) to hand over confidential peer reviews as part of litigation involving two controversial painkillers.

Pfizer, the world's largest drug company, subpoenaed the medical journal last May to surrender peer reviews, the names of peer reviewers and internal editorial deliberations for 11 recent papers related to the painkillers Celebrex (celecoxib) and Bextra (valdecoxib). It also wants all other manuscripts the journal has received involving either drug. Most of the studies were published in 2005 and 2006 after Bextra and Vioxx (another drug in the same class of COX-2 inhibitors) were withdrawn because of serious side effects.

Pfizer, based in New York, is defending Celebrex and Bextra in lawsuits charging that they caused heart attacks and strokes. Bextra was pulled from the market in 2005; Celebrex is still available. The drugmaker is trying to obtain the NEJM reviews as part of its defence in the US district court in northern California, where several lawsuits relating to the drugs have been consolidated.

In November, the NEJM turned over 246 pages of documents, but included only its communications with the named authors of the papers, and their financial disclosures.

Pfizer offered to remove the names of individual peer reviewers from any documents

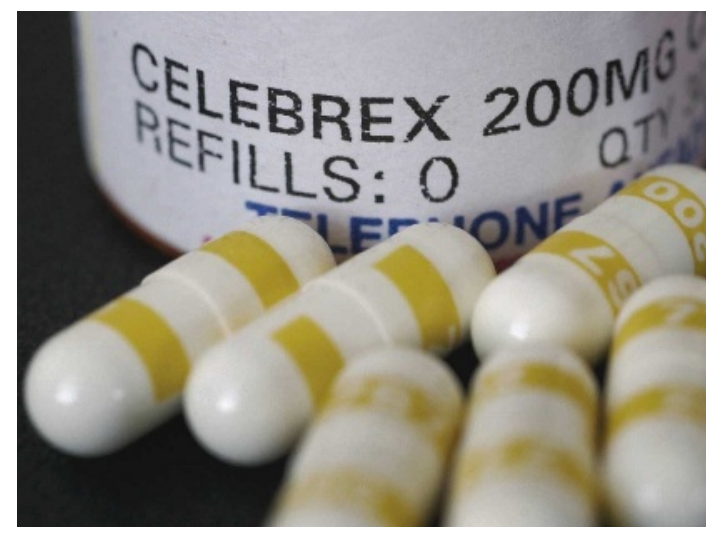

Pfizer wants to obtain peer reviews relating to Celebrex. the journal provided - but the NEJM still resisted. In January, the drug company filed a motion to force the NEJM to hand over the peer reviews and any other manuscripts. "Scientific journals such as NEJM may have received manuscripts that contain exonerating data for Celebrex or Bextra, which would be relevant for Pfizer's causation defence," its lawyers wrote. "The public has no interest in protecting the editorial process of a scientific journal, particularly not when doing so prevents a defendant from access to potentially exonerating evidence."

Responding in an affidavit, Jeffrey Drazen, NEJM editor-in-chief, argued that if the company prevails, there could be "serious adverse consequences" for the scientific peer-review process, including the ability of journals to recruit reviewers, who will be wary of "the possibility that their volunteer work would land them in the middle of litigation". He wrote that removing names would not be enough to disguise reviewers, given the

\section{Bright hopes pervade dark matter}

Physicists have again returned empty-handed from a search for the 'dark matter' that is thought to fill the cosmos. But the latest null result hasn't dimmed their enthusiasm - or their plans for a new generation of detectors.

Since the 1970s, theorists have predicted the existence of massive particles that rarely,

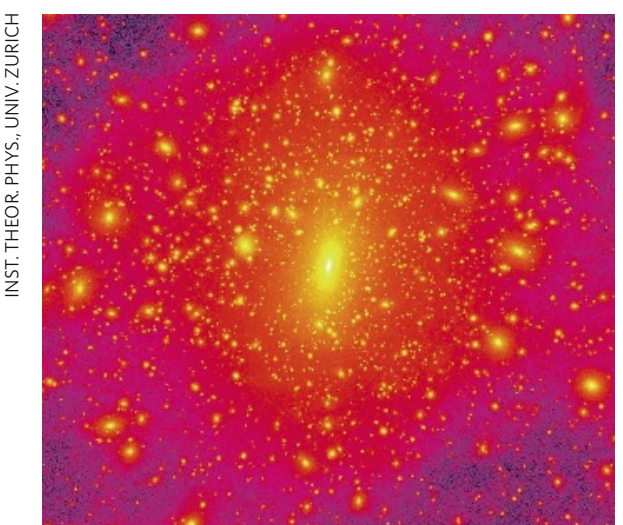

Computer simulation of the distribution of dark matter that is thought to fill the Universe. if ever, interact with normal matter. This dark matter is believed to be responsible for slowing the rotation of galaxies and makes up about $85 \%$ of matter in the Universe. Physicists have devised a host of experiments to find dark matter, but to date, nobody has been able to detect it directly (see Nature 448, 240-248; 2007).

The latest non-findings met with spontaneous applause at a conference on 22 February in Marina del Rey, California. The results came from Cryogenic Dark Matter Search II (CDMSII) one of the world's most advanced dark-matter detectors, located in the Soudan mine in Minnesota. CDMSII uses giant crystals of germanium and silicon that physicists hope will ring out when struck by a dark-matter particle.

The crystals are kept more than 700 metres underground in order to shield them from disruptive cosmic radiation. A previous generation of CDMS detectors delivered nothing, and the new bigger and better crystals are only now beginning to reach sensitivities at which they might realistically see a dark-matter particle, says Bernard Sadoulet, a physicist at the
University of California, Berkeley, who leads the CDMSII collaboration. "We really are entering the core of the interesting territory."

The results are not entirely surprising, says Elena Aprile, a physicist at Columbia University in New York city who is working on a rival experiment called XENON10. The darkmatter particles could still be well below the experiment's threshold, she says. "Maybe it's just a little too insensitive still."

Sadoulet says the CDMSII detector should reach up to four times its present sensitivity later this year, and Aprile says a new, larger XENON100 detector could do better still. But detecting the particles may require sensitivities hundreds of times beyond even these levels. That will probably mean a next generation of detectors. Sadoulet and Aprile both say they have proposals for third-generation detectors, which are expected to cost tens of millions of dollars.

But the lack of detection and rising costs raise another spectre for the dark-matter hunters - what if the particles aren't there? Or what if they don't interact with regular matter? 
small number of experts in any one area, who can easily identify each other through their arguments.

Similarly, he argued, free-flowing discussion among NEJM editors would be stemmed "if litigants were able to pick apart this internal editorial process to serve their own needs".

Scientists and editors have rallied to the NEJM's cause. Donald Kennedy, editor-in-chief of Science, calls Pfizer's efforts a "fishing expedition" because of its failure to specify what it is looking for. If Pfizer prevails, says Marcia Angell, a senior lecturer in social medicine at Harvard Medical School and a former editor of the NEJM, "it would undermine the whole system of peer review, which depends utterly on confidentiality".

Aravinda Chakravarti, a computational biologist and geneticist at Johns Hopkins University in Baltimore, Maryland, says that he can imagine "exceptional circumstances" in which a manuscript review could be submitted as part of litigation, with any potentially identifying information removed. But with Pfizer requesting all of the reviews on 11 papers and possibly more, he says: "I am worried about the precedent. This may benefit Pfizer, but science loses in a big way."

A ruling is expected on 13 March. Meredith Wadman

Nobody knows exactly where dark matter lives in the Milky Way, although it is likely to exist in our Solar System in some shape or form, according to Ben Moore, a theorist at the University of Zurich in Switzerland. But he adds that many proposed versions of the stuff would never interact with a germanium crystal - or anything else. "It's a gamble," he says. "If dark matter is one of those alternative candidates, then they're not going to see anything."

Sadoulet is the first to admit that this may be the case. Still, he hastens to add, there is good reason to look, especially because several other experiments may soon provide further clues. A satellite called the Gamma-ray Large Area Space Telescope will launch later this year, and may provide evidence of dark matter 'annihilating' in the cosmos. Also this year, the Large Hadron Collider, the world's largest particle accelerator, which is located at CERN near Geneva in Switzerland, will start looking for signals that could confirm the existence of some classes of dark-matter particle.

The risk of coming up empty-handed nags at the field, Sadoulet says. But if something is found, "it will be a new start for particle physics".

Geoff Brumfiel

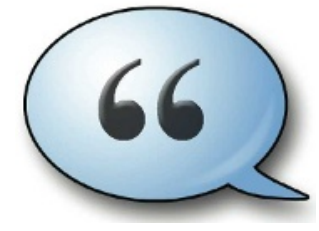

HAVE YOUR SAY

Comment on any of our news stories, online.

www.nature.com/news

\section{Entomologists stifled by Indian bureaucracy}

An international collaboration to study insects in the Western Ghats mountains in southern India has been unable to get off the ground because of government concerns over biopiracy.

The Indian-American project aims to sample insects from different ecosystems at various elevations, and incorporate about 200,000 specimens into national insect collections. "We have already identified 24 taxonomists from all over the world who are willing to work on this project," says Priyadarsanan Dharmarajan, a taxonomist at the Ashoka Trust for Research in Ecology and the Environment in Bangalore, who leads the Indian team.

But the project has stalled because India's National Biodiversity Authority (NBA) has denied the Ashoka Trust permission to export the specimens, despite assurances that they would be returned to India after identification. "We have to send the specimens abroad for identification as we do not have the expertise at home," Dharmarajan says.

Indian biodiversity rules guiding foreign collaborations require permission from the NBA before specimens can be exported. Under the Biological Diversity Act, specimens must not be deposited in international museums but kept only in designated repositories in India.

Now Paul Tinerella, insect collection manager at the Illinois Natural History Survey in Champaign, which is involved in the project, has informed the Ashoka Trust that the venture is "doomed" without the exit permits from the NBA or relevant supporting documents from the Indian government. "Biodiversity assessment is critical to wise land-use planning and without the basics of a sound taxonomic framework across the spectrum of life, biodiversity assessment is extremely faulty," says Michael Irwin, an insect ecologist at the Illinois Natural History Survey.

The draconian regulations on the free exchange of specimens could isolate Indian biodiversity researchers, says K. D. Prathapan, a taxonomist at the Kerala Agricultural University. "This could totally isolate Indian biodiversity researchers.” Prathapan's own recent discovery of three new species of flea beetle in India "would have been impossible" but for the loan of specimens from five international museums in four countries.

Krishnamoorthy Venkataraman, secretary of the NBA, says that the rules aim to fight biopiracy and not to stop basic research. "There is no restriction on collection or export of a few specimens for research," he told Nature. "But exporting 200,000 specimens is not permissible." The NBA encourages Indian scientists to send photographs or digital images to collaborators abroad instead of actual specimens, he says.

Dharmarajan hopes that the Indian government will follow the example of Brazil, which repealed its initially tough rules for biological specimens after protests by scientists.

K. S. Jayaraman

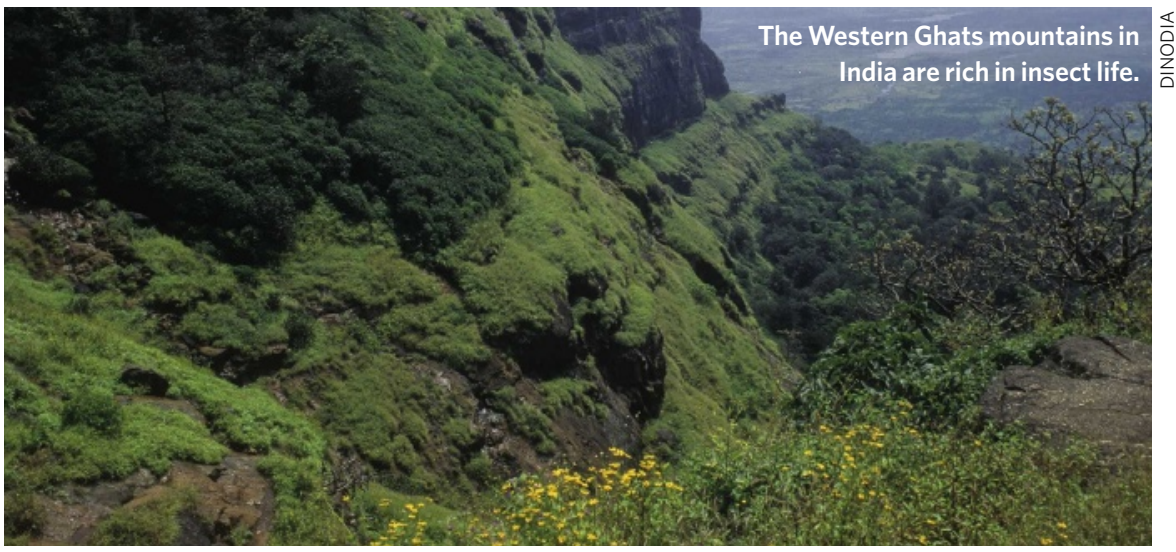

